Title: Towards deracemization in the absence of grinding through crystal transformation, ripening and racemization

Authors: Christos Xiouras ${ }^{\dagger}$, Emma Van Cleemput ${ }^{\dagger}$, Andries Kumpen ${ }^{\dagger}$, Joop H. Ter Horst ${ }^{\ddagger}$, Tom Van Gerven $^{\dagger}$ and Georgios D. Stefanidis ${ }^{\dagger *}$

$\uparrow$ Process Engineering for Sustainable Systems (ProcESS), Department of Chemical Engineering KU Leuven, Celestijnenlaan 200F, 3001 Leuven, Belgium

+ EPSRC Centre for Innovative Manufacturing in Continuous Manufacturing and Crystallisation (CMAC), Strathclyde Institute of Pharmacy and Biomedical Sciences (SIPBS), Technology and Innovation Centre, University of Strathclyde, 99 George Street, Glasgow G1 1RD, U.K.

*Correspondence to: Georgios D. Stefanidis

Tel: $+32(0) 16321007$

E-mail: Georgios.Stefanidis@cit.kuleuven.be

Type of Manuscript: Article

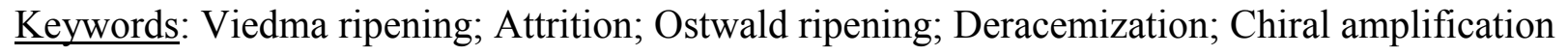

Abstract: New insights into the obscure mechanisms of solid-state deracemization phenomena are obtained by crystal ripening experiments that, contrary to standard techniques, exclude attrition enhancement (grinding). The results point out that small particles and an initial size imbalance between the two enantiomeric crystal populations can intensify the rate of solid-state enantiomeric enrichment even in the absence of intermediate actions (e.g. grinding or thermal cycling). On this ground, a new process that creates such initial conditions is designed and exemplified for the proteinogenic glutamic acid. As a first step, racemic compound solvate (DL-glutamic acid monohydrate) crystals are completely converted to small-sized conglomerate anhydrate crystals, in the presence of larger seeds of a single chirality. After the transformation is complete and the racemization catalyst is added, the suspension contains an equal number of small-sized conglomerate crystals of both enantiomers together with the larger seeds of the preferred enantiomer. Over time, the large crystals of the preferred enantiomer tend to grow at the expense of smaller ones, which dissolve. This, combined with the fast racemization, leads to enantiomeric enrichment. The possible occurrence of enantioselective agglomeration between small and seed crystals speeds up this process by removing small crystals of the preferred enantiomer. Since most amino acids and several other pharmaceutical compounds are known to form metastable racemic hydrate crystals, it is expected that this new method is readily applicable to a variety of compounds. In addition, the process provides a technically simpler and more scalable route to enantiomeric enrichment compared to attrition-enhanced deracemization and its applicability extends to the wider pool of compounds that crystallize as racemic crystals. 


\title{
Towards deracemization in the absence of grinding through crystal transformation, ripening and racemization
}

\author{
CHRISTOS XIOURAS ${ }^{\dagger}$, EMMA VAN CLEEMPUT ${ }^{\dagger}$, ANDRIES KUMPEN ${ }^{\dagger}$, JOOP H. TER HORST ${ }^{\ddagger}$, \\ TOM VAN GERVEN ${ }^{\dagger}$, AND GEORGIOS D. STEFANIDIS ${ }^{\dagger,}$
}

${ }^{\dagger}$ Process Engineering for Sustainable Systems (ProcESS), Department of Chemical Engineering KU Leuven, Celestijnenlaan 200F, 3001 Leuven, Belgium

${ }^{*}$ EPSRC Centre for Innovative Manufacturing in Continuous Manufacturing and Crystallisation (CMAC), Strathclyde Institute of Pharmacy and Biomedical Sciences (SIPBS), Technology and Innovation Centre, University of Strathclyde, 99 George Street, Glasgow G1 1RD, U.K.

*Correspondence to: Georgios D. Stefanidis

KEYWORDS: Viedma ripening; Attrition; Ostwald ripening; Deracemization; Chiral amplification

\begin{abstract}
New insights into the obscure mechanisms of solid-state deracemization phenomena are obtained by crystal ripening experiments that, contrary to standard techniques, exclude attrition enhancement (grinding). The results point out that small particles and an initial size imbalance between the two enantiomeric crystal populations can intensify the rate of solid-state enantiomeric enrichment even in the absence of intermediate actions (e.g. grinding or thermal cycling). On this ground, a new process that creates such initial conditions is designed and exemplified for the proteinogenic glutamic acid. As a first step, racemic compound solvate (DL-glutamic acid monohydrate) crystals are completely converted to small-sized conglomerate anhydrate crystals, in the presence of larger seeds of a single chirality. After the transformation is complete and the racemization catalyst is added, the suspension contains an equal number of small-sized conglomerate crystals of both enantiomers together with the larger seeds of the preferred enantiomer. Over time, the large crystals of the preferred enantiomer tend to grow at the expense of smaller ones, which dissolve. This, combined with the fast racemization, leads to enantiomeric enrichment. The possible occurrence of enantioselective agglomeration between small and seed crystals speeds up this process by removing small crystals of the preferred enantiomer. Since most amino acids and several other pharmaceutical compounds are known to form metastable racemic hydrate crystals, it is expected that this new method is readily applicable to a variety of compounds. In addition, the process provides a technically simpler and more scalable route to enantiomeric enrichment compared to attrition-enhanced deracemization and its applicability extends to the wider pool of compounds that crystallize as racemic crystals.
\end{abstract}

\section{INTRODUCTION}

Synthesis of enantiopure compounds is a major challenge for the pharmaceutical and fine chemical industries ${ }^{1}$. Among the various approaches to obtain single enantiomers, separation of racemates by means of crystallization processes is the most widely employed technique at large scale ${ }^{2}$. When the racemate crystallizes as a mixture of enantiopure crystals (racemic conglomerate), near-equilibrium ripening processes combined with solution-phase racemization can be employed to completely convert the racemic mixture into one chirality, in a socalled deracemization process ${ }^{3}$. Viedma demonstrated such a process for the achiral $\mathrm{NaClO} 3$ that forms chiral conglomerate crystals, by using wet-milling in isothermal conditions ${ }^{4}$. Since then, variants of this method, now termed as Viedma ripening 5 , have been applied to chiral organic compounds that crystallize as (metastable) conglomerates and racemize in solution ${ }^{6}$ 18. The method has also been combined with a reaction between achiral substrates to deliver an enantiopure product ${ }^{19}$. The mechanisms of Viedma ripening are generally believed to include growth-dissolution due to size dependence of solubility, agglomeration, breakage and solution phase racemization $5,9,20,21$. Besides the practical application of Viedma ripening, it has also been considered by some as a likely enantiomeric excess amplification mechanism that could possibly aid in unravelling the enigmatic origin of homochirality in biologically relevant molecules ${ }^{22,23}$.

Even though Viedma ripening is a promising method to obtain enantiopure compounds, it suffers from two major limitations: a) it is only applicable to conglomerate forming compounds (5-10\% of chiral organic molecules); and b) scale-up is challenging, as one would have to ensure that the attrition rate attained at the lab scale can be transferred to larger scales and that the crystallizer has the mechanical properties to withstand the stress involved. In addition, further process steps may be required to separate the grinding media from the solid product. Current research focuses on alternative methods to intensify or replace grinding, such as ultrasound ${ }^{24,25}$, or thermal treatments (spatial ${ }^{26,27}$ or temporal ${ }^{28-30}$ temperature variations). On the other hand, studies try to extend the process to compounds that form racemic crystals (mixed crystals of both enantiomers), by studying racemic crystal transformations to conglomerates, followed by grinding ${ }^{12,18}$.

Crystal form transformations are most often solution-mediated and their rate depends on the interplay between the rate of dissolution of the metastable phase and the nucleation and 
growth rate of the stable phase ${ }^{31,32}$. Furthermore, if large solubility differences between the two phases exist, high supersaturation values can be attained, favoring crystal nucleation over growth leading to very small final crystal sizes ${ }^{33}$. The link between crystal size and deracemization has been highlighted in several studies of Viedma ripening ${ }^{9,25}$. Small mean crystal size and a bias in the crystal size distributions of the two enantiomers are generally preferred to attain fast enantiomeric enrichment, because: a) smaller particles tend to dissolve faster; therefore in the presence of fast racemization, the dissolution of the minor enantiomer is accelerated; and b) a larger size difference between the two enantiomers provides a larger drive for growth of the major enantiomer via Ostwald ripening ${ }^{5,21}$. On this basis, we hypothesized that a swift solutionmediated transformation of racemic crystals to conglomerates taking place preceding the deracemization process could significantly reduce the mean crystal size in a suspension. If the method is also combined with seeding of single chirality crystals, a sufficient bias in the crystal size distributions of the two enantiomers might ensue. The combination of small mean crystal size and a bias between the crystal size distributions of the enantiomers might effectively speed up the deracemization process to such extent that will allow grinding to be minimized or even be excluded. Importantly, such a process would extend the applicability of solid-state deracemization techniques from conglomerate forming compounds to the wider pool of chiral compounds that form racemic crystals. The hypothesis is tested experimentally for glutamic acid, a proteinogenic amino acid essential to neurotransmission and metabolism ${ }^{34}$.

Glutamic acid is one of the few amino acids that crystallize as a metastable conglomerate at room temperature, although it can crystallize also in two racemic compounds: the DLglutamic acid monohydrate ${ }^{35}$ and the anhydrous DL-glutamic acid ${ }^{36}$. Glutamic acid can be efficiently racemized in acidic media ${ }^{37}$ and relatively mild temperatures in the presence of catalytic aldehydes, via the formation of the Schiff base ${ }^{38}$. Although several studies have investigated the polymorph transformation for glutamic acid conglomerate ${ }^{39-41}$, very few have studied the racemic hydrate to conglomerate transformation. Spix et al. recently showed that in acetic acid, the racemic compound monohydrate is the least stable form and converts quickly to the anhydrous conglomerate, which in turn converts very slowly to the anhydrous racemic compound (most stable form) ${ }^{12}$. The conglomerate was shown to be sufficiently stable to prevent the formation of the racemic compound anhydrate, even in the presence of grinding. As a result, in the same study, it was also shown that enantiopure glutamic acid can be obtained by Viedma ripening starting from a mixture of conglomerate and hydrate crystals in acetic acid using salicylaldehyde as racemization catalyst.

Herein, we investigate whether the use of a solution-mediated racemic crystal transformation prior to deracemization can be used to modify the initial crystal size distribution and promote enantiomeric enrichment without the need of intense grinding. To achieve this, we perform sets of chiral amplification experiments without grinding for the model compound glutamic acid using two different initial preparation methods that start from different crystalline forms. Further, the transformation of the DL-glutamic acid monohydrate crystals to the conglomerate anhydrate is studied in more detail. Finally, chiral amplification experiments using an artificial bias in the crystal size distributions of the two enantiomers offer important insight into the mechanisms of chiral symmetry breaking in heterogeneous systems.

\section{EXPERIMENTAL SECTION}

Model system preparation prior to chiral amplification. Prior to the chiral amplification experiments, two preparation methods were applied. In both methods, a suspension of glutamic acid crystals with an initial enantiomeric excess of either $62.7 \%$ or $21.9 \%$ was created by adding $10 \mathrm{~mL}$ of acetic acid into a jacketed reactor vessel. Subsequently, the suspension was heated to $70{ }^{\circ} \mathrm{C}$ (heating period of approximately 4 minutes) using a thermostatic bath, while magnetically stirring at $1200 \mathrm{rpm}$ and was maintained at this temperature for 30 min. After the initial $30 \mathrm{~min}$ at $70{ }^{\circ} \mathrm{C}$, the first sample $(\mathrm{t}=0)$ was taken and the temperature was increased to $90{ }^{\circ} \mathrm{C}$ (heating period of approximately 2 minutes).

Preparation method without crystal transformation (method A). In preparation method A, conglomerate D- and L-glutamic acid crystals were used to create the initial enantiomeric excess. Additionally, a small amount of MilliQ water $(26 \mathrm{mg}$ and $52 \mathrm{mg}$ for enantiomeric excesses of $62.7 \%$ and $21.9 \%$, respectively) was added, to ensure comparable conditions with method B, where the DL-glutamic acid hydrate transformation unavoidably results in some water being present in the system. The total mass of the added solid together with the water was always kept at $600 \mathrm{mg}$.

Preparation method with crystal transformation (method B). In preparation method B, DL-glutamic acid hydrate was combined with conglomerate L- or D-glutamic acid to create the initial enantiomeric excess (total mass of solid: $600 \mathrm{mg}$ ). At the conditions tested, DLglutamic acid monohydrate converts completely to the anhydrous Dand L-glutamic acid conglomerates as checked with XRD and also reported by Spix et al ${ }^{12}$. Since for the DL-glutamic acid monohydrate, one mole of $\mathrm{H} 2 \mathrm{O}$ is present for every glutamic acid molecule, the actual amount of solid glutamic acid after the transformation is slightly less than $600 \mathrm{mg}$, with some water also being released into the system.

Chiral amplification experiments without grinding. After the respective preparation method was applied, the chiral amplification experiments were initiated by adding the racemization catalyst, salicylaldehyde (140 mg). All chiral amplification experiments were conducted at the same conditions and only the preparation method was different. During these experiments, the temperature was controlled at $90{ }^{\circ} \mathrm{C}$ for the entire duration of the experiments (maximum experimental duration: $30 \mathrm{~h}$ ) and the solid phase was regularly sampled. Suspension samples from different locations of the vessel (total of $250 \mu \mathrm{L}$ ) were taken over time, vacuum filtered over a P4 glass filter to remove the solvent and washed using $2 \mathrm{~mL}$ of acetone. Prior to the chiral HPLC analysis, the resulting crystals were dried overnight by means of an oven set at $40^{\circ} \mathrm{C}$.

Determination of the solid phase enantiomeric excess by chiral HPLC analysis. Prior to the analysis, the dried solid samples were dissolved in MilliQ water to give a solution of $1 \mathrm{mg} / \mathrm{mL}$ concentration of glutamic acid. Subsequently, the samples were analyzed using an HPLC apparatus (Agilent 1100 Series) with a Chirex 3126 column. D- and L-glutamic acid concentrations were measured using a Diode Array Detector (DAD) at $254 \mathrm{~nm}$. The eluent was $2 \mathrm{mM} \mathrm{CuSO} 4$ in ultrapure (MilliQ) water at a flow rate of $1 \mathrm{~mL} / \mathrm{min}$ and the column temperature was controlled at $40{ }^{\circ} \mathrm{C}$. The injection volume was 20 $\mu \mathrm{L}$. The enantiomeric excess was calculated based on the detector response peak areas for D- and L-glutamic acid as: e.e. $=\left|A_{D}-A_{L}\right|$ / $\left(A_{D}-A_{L}\right)$.

Crystal size distribution (CSD) measurement. After the end of the experiments, all remaining crystals were collected using vacuum filtration and dried, as mentioned above. The dry crystals were dispersed in ethanol at room temperature and were immediately subjected to measurement of the Crystal Size Distribution (CSD) using a Malvern Mastersizer S with MS14 sample dispersion unit. Crystal size, shape and morphology were also checked by light microscopy pictures, taken using an Olympus BX41 microscope coupled with a Hamamatsu C4742-95 Digital Camera Controller at different magnifications. 

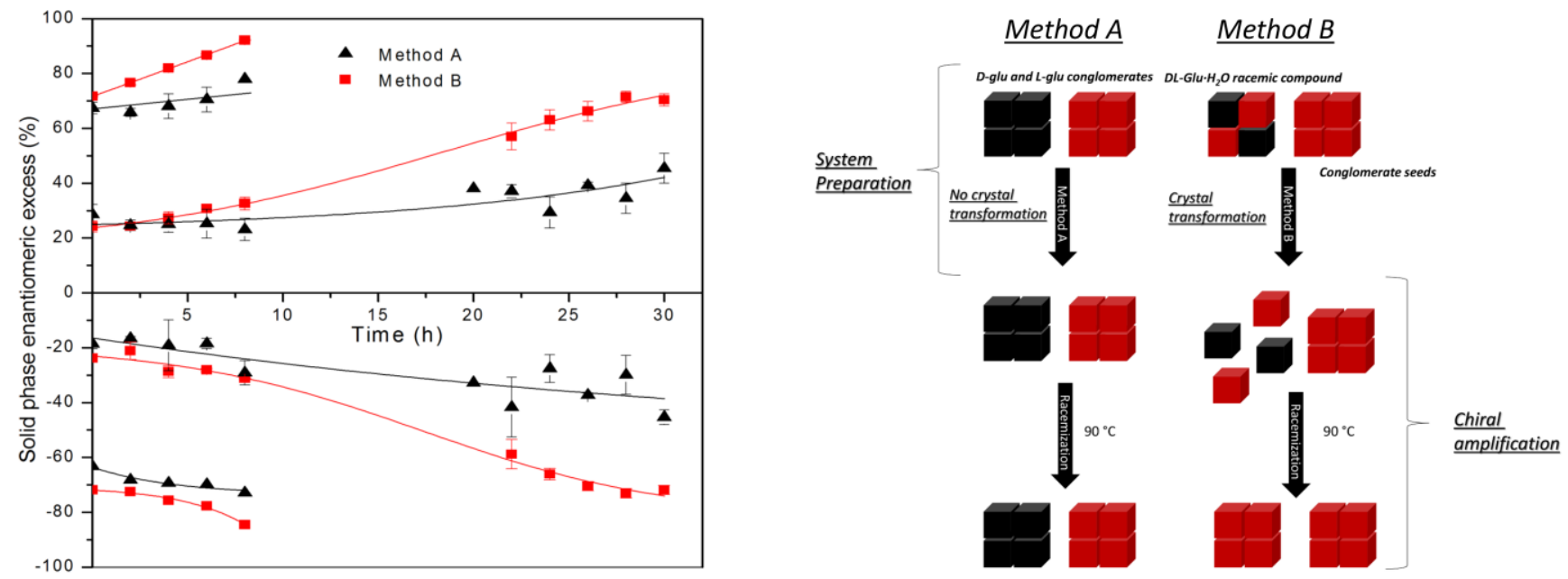

Figure 1. Left: Evolution of solid-phase enantiomeric excess for glutamic acid crystals at $90{ }^{\circ} \mathrm{C}$ without grinding at the same conditions using two different initial preparation methods (a minus sign is assigned to a D-glutamic acid enantiomeric excess). Preparation method A (black triangles): No crystal transformation takes place. Preparation method B (red squares): Experiments with an initial transformation of DL-glutamic acid monohydrate crystals to conglomerates in the presence of D- or L-glutamic acid seeds prior to chiral amplification. Right: Simplified scheme of the underlying mechanisms in the deracemization process for glutamic acid using preparation methods A and B.

XRPD analysis for the determination of crystal form. For the transformation of the DL-glutamic acid hydrate crystals to the anhydrous conglomerates, separate experiments were done, in which $2 \mathrm{~g}$ of DL-glutamic acid hydrate were stirred at $1200 \mathrm{rpm}$ in $10 \mathrm{~mL}$ of acetic acid. Temperature was increased to $70{ }^{\circ} \mathrm{C}$ and kept for $30 \mathrm{~min}$. Subsequently, temperature was increased to $90{ }^{\circ} \mathrm{C}$ and was kept for $24 \mathrm{~h}$. The conditions of these experiment were similar to the chiral amplification experiments. Samples were taken for XRPD analysis after 30 min at $70{ }^{\circ} \mathrm{C}, 2 \mathrm{~h}$ at $90{ }^{\circ} \mathrm{C}$ and $24 \mathrm{~h}$ at $90{ }^{\circ} \mathrm{C}$. The crystal form was determined by X-Ray powder diffraction (XRPD), using a Philips PW1830 diffractometer with Bragg/Brentano theta-2theta setup, $\mathrm{CuK} \alpha$ radiation, $45 \mathrm{kV}, 30 \mathrm{~mA}$ and a graphite monochromator. The scan range was between 10 and $40^{\circ}$, a step size of 0.01 was used and the time/step was $2 \mathrm{~s}$.

\section{RESULTS AND DISCUSSION}

Effect of the preparation method on chiral amplification without grinding. Two sets of experiments were designed to investigate whether chiral symmetry breaking of glutamic acid crystals is possible in the absence of any grinding using two initial preparation methods. These experiments were performed at the same conditions starting from several values of the initial enantiomeric excess and the results are presented in Figure 1. In preparation method A, no crystal transformation takes place, while in preparation method B, the DL-glutamic acid monohydrate crystals fully convert to anhydrate conglomerate crystals ${ }^{12}$. Furthermore, in preparation method B, the addition of the larger seed crystals combined with the change in crystal form can create a bias in the crystal size distribution of the enantiomers. When the preparation methods are complete ( $t=0 \mathrm{~h}$ in Figure 1), chiral amplification experiments are performed by adding the racemization catalyst to the prepared suspension (0h-30h in Figure 1).

Figure 1 shows that in all experiments carried out after preparation method A (black triangles in Figure 1), increase in the enantiomeric excess is very slow for the times studied. As an example, for the experiment starting from an enantiomeric excess of $28 \%$, a value of $32 \%$ is obtained after 24 hours. Prolonged time for this experiment did not result in a significant increase in the enantiomeric excess. In the absence of any grinding, the rate of the enantiomeric excess increase is strongly suppressed as it has been explained in several experimental ${ }^{4,25,42}$ and modelling ${ }^{21,43}$ studies of Viedma ripening. As an example of the effect of attrition, Noorduin et al. found that the rate of enantiomeric excess increase was approximately 3.5-fold higher for a chiral organic compound, when the amount of grinding media doubled ${ }^{42}$.

Conversely, in every experiment carried out after preparation method B (red squares in Figure 1), substantial increase in the enantiomeric excess in time was observed in the absence of grinding. Indicatively, for an experiment starting from an enantiomeric excess of $25 \%$, an increase to $63 \%$ was observed in 24 hours. For a similar experiment in the study of Spix et al., but in the presence of grinding with glass beads, enantiomeric excess increased from $25 \%$ to approximately $85 \%$ in 24 hours ${ }^{12}$. Considering these differences, our results indicate that enantiomeric enrichment is possible to occur even in the absence of grinding. The final chiral outcome is determined by the enantiomer present as the glutamic acid anhydrate seeds. The results obtained for D- and L-glutamic acid are symmetric with regard to the enantiomeric excess evolution profile, in accordance with previous studies ${ }^{6,12}$.

For the experiments carried out after preparation method B that start at a lower initial enantiomeric excess, the enantiomeric excess levels off and even decreases (not shown) after approximately 28 hours, similarly to previous Viedma ripening results for glutamic acid ${ }^{12}$. This effect was not observed when method A was used. Eventually, however, decrease in enantiomeric excess is expected for the experiments carried out after method A experiments as well, since the conglomerate crystal form has been shown to be metastable and in time will transform into the stable anhydrous racemic compound, which cannot be deracemized ${ }^{12}$. The rate of this transformation inevitably limits the time window in which enantiomeric enrichment is possible for this system. 
Viedma et al. have reported relatively fast enantiomeric excess increase in the absence of grinding for aspartic acid. In their study though, a heating plate was used to create a strong temperature gradient, which according to the author's interpretation enhanced crystal dissolution in hot zones and crystal growth in cold zones, effectively leading to deracemization ${ }^{26}$. Temporal temperature variations have also been shown to induce enantiomeric enrichment in a similar manner ${ }^{28,29,44}$. However, such effects can be excluded in the present study, since a heating jacket was used to create a homogeneous and controlled temperature profile in the reactor, which remained essentially constant for the entire duration of the experiments.

Partial dissolution or decomposition of a scalemic mixture of conglomerate crystals can also lead to an increase in the solid phase enantiomeric excess, even in the absence of racemization, since such mixtures tend to dissolve with a eutectic enantiomeric excess of $0 \%$. To make sure that increase in the enantiomeric excess is not only due to partial dissolution of the scalemic mixture at the temperature of the experiments, the final solid yield was determined in separate experiments starting from a prepared enantiomeric excess of $62.7 \%$. These experiments were performed at the same conditions as the chiral amplification experiments using preparation method B and starting with a high initial enantiomeric excess in order to reach close to enantiopurity. A solid yield of $\approx 78 \%$ with enantiomeric excess $>97 \%$ was obtained in these experiments. The mass of the nearly enantiopure solid obtained in the end of the experiments was $452 \mathrm{mg}(\approx 26 \%$ higher than the amount of seed crystals initially added), while the mass of the counter enantiomer was only $6 \mathrm{mg}$. This confirms that partial dissolution of the racemic mixture, although it plays a role, it is alone insufficient to explain the observed increase in the enantiomeric excess. Loss of solid is mainly due to the solubility of glutamic acid in the solvent as reported by Spix et al. and may be circumvented by working at lower temperatures ${ }^{12}$.

The experimental results obtained highlight several aspects of the enantiomeric enrichment mechanism and the influence of the initial preparation method on its outcome. When preparation method $\mathrm{B}$ precedes the experiment, the rate of enantiomeric excess increase is comparably fast to processes conducted under enhanced attrition, i.e. using glass beads in combination with stirring. At the same time, when method A precedes the experiment, enantiomeric excess hardly increases. The seemingly faster rate obtained using method B versus method $\mathrm{A}$ at the same conditions is in accordance to our initial hypothesis that in the presence of seeds, a solution-mediated transformation of racemic crystals to conglomerates affects the initial crystal size distribution to such extent that ultimately enables enantiomeric enrichment.

Evolution of crystal size during the chiral amplification process. Figure 2 presents the initial (before preparation) and final (after both preparation and chiral amplification) crystal size distributions for an experiment conducted after using preparation method A. The final volume- and number-based crystal size distributions, measured after the end of this experiment, appear to be very similar to the initial ones, indicating that crystal attrition, e.g. due to magnetic stirring, is quite restricted at the experimental conditions tested. The mean crystal size of the conglomerate L- and D-glutamic acid crystals, initially used to start this experiment, is measured at $d_{4,3}=187$ $\mu \mathrm{m}$ and $d_{1,0}=9.3 \mu \mathrm{m}$. The commercial D- and L-glutamic acid conglomerate crystals, which were used initially have very similar crystal size distributions (Figure 2 blue line and Figure
3 blue line); thus there is no significant bias to one enantiomer due to differences in crystal size, as it has been shown to be possible in another work ${ }^{8}$. After 30 hours only a slight decrease in the mean crystal size is observed, measured at $d_{4,3}=$ $145 \mu \mathrm{m}$ and $d_{1,0}=8.4 \mu \mathrm{m}$. The small decrease in crystal size is attributed to the partial dissolution of the crystals due to the initial temperature increase and to some inevitable (minor) breakage occurring due to crystal collisions in the mixed suspension.

Figure 3 presents the initial (before preparation) and final (after both preparation and chiral amplification) crystal size distributions for an experiment carried out after using preparation method B. The initial size distribution reported is that of the added conglomerate seeds of L- glutamic acid (without the hydrate) in order to allow for size comparison of the same crystal type since the final solid mixture contains only the conglomerate. It is found that the crystal size distribution shifts towards a smaller final size range when method B is used, with the final mean crystal size being $d_{4,3}=63 \mu \mathrm{m}$ and $d_{1,0}=1.41 \mu \mathrm{m}$. A considerable number of smaller particles is detected at the end of the process, ranging from a size of 0.5 to $5 \mu \mathrm{m}$.

The observed evolution of crystal size using preparation method B and subsequent chiral amplification bears a strong resemblance to attrition-enhanced deracemization experiments reported in the literature ${ }^{5,9}$. In such experiments, the mean crystal size rapidly decreases and the crystal size distribution broadens, as new smaller particles emerge at different sizes due to the breakage of larger ones. Similarly, using preparation method $\mathrm{B}$, mean particle size is reduced and crystal size distribution broadens, not due to breakage, but due to the formation of new smaller particles. On the contrary, when using preparation method A, crystal size only slightly decreases and no significant increase in the enantiomeric excess is observed. Since in preparation method $\mathrm{B}$, the transformation of the DLglutamic acid monohydrate crystals to the L- and D-glutamic acid anhydrous conglomerates takes place, we hypothesized that the emergence of the small particles is a result of the transformation.

DL-glutamic acid monohydrate transformation. In order to investigate the transformation, a new experiment was designed at similar conditions to those of preparation method B and the subsequent chiral amplification experiments, this time starting only from the DL-glutamic acid hydrate crystals in the absence of any racemization catalyst. The resulting crystals were analyzed using X-ray powder diffraction (XRPD), optical microscopy and laser diffraction. Figure 4 presents the XRPD patterns of several samples extracted at different times during this experiment. It appears that already after 30 min under stirring at $70{ }^{\circ} \mathrm{C}$, the hydrate fully dissolved, while the conglomerate formed. This finding confirms that in all chiral amplification experiments preceded by preparation method B, crystal transformation is complete prior to the start of the enantiomeric enrichment process. The fast transformation of the DL-glutamic acid crystals at elevated temperatures mostly acts to supply the mixture with the $\mathrm{D}$ and $\mathrm{L}$ conglomerates required for the chiral amplification experiments. Figure 4 also shows that the conglomerate structure is preserved at $90{ }^{\circ} \mathrm{C}$ up to 24 $\mathrm{h}$, which is most of the duration of the chiral amplification experiments. It is noted that for the same transformation experiment at room temperature, XRPD analysis revealed a mixture of the hydrate and the conglomerate for more than 3 hours, after which the experiment was terminated. 

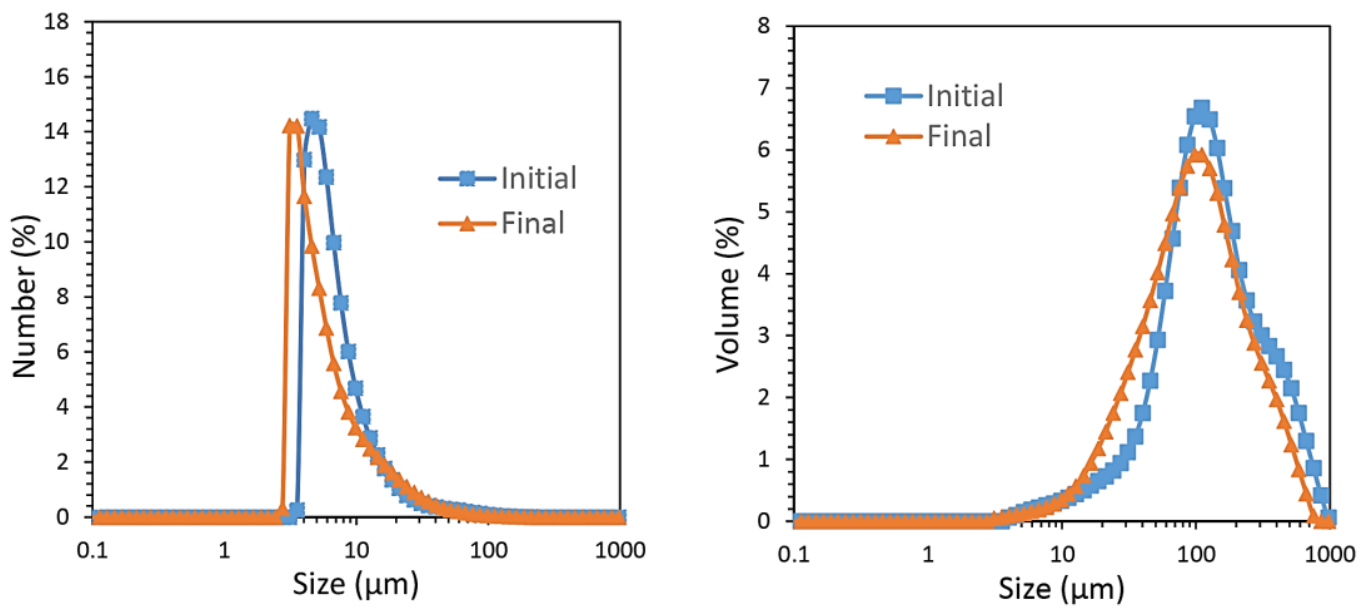

Figure 2. Evolution of number- (left) and volume-based (right) crystal size distribution (CSD) measurements (\%) by laser diffraction for a 30-hour chiral amplification experiment after using preparation method A. Initial CSD is that of the mixture of L- and Dglutamic acid crystals added prior to the preparation. Final CSD is the one measured after both preparation and chiral amplification experiment.
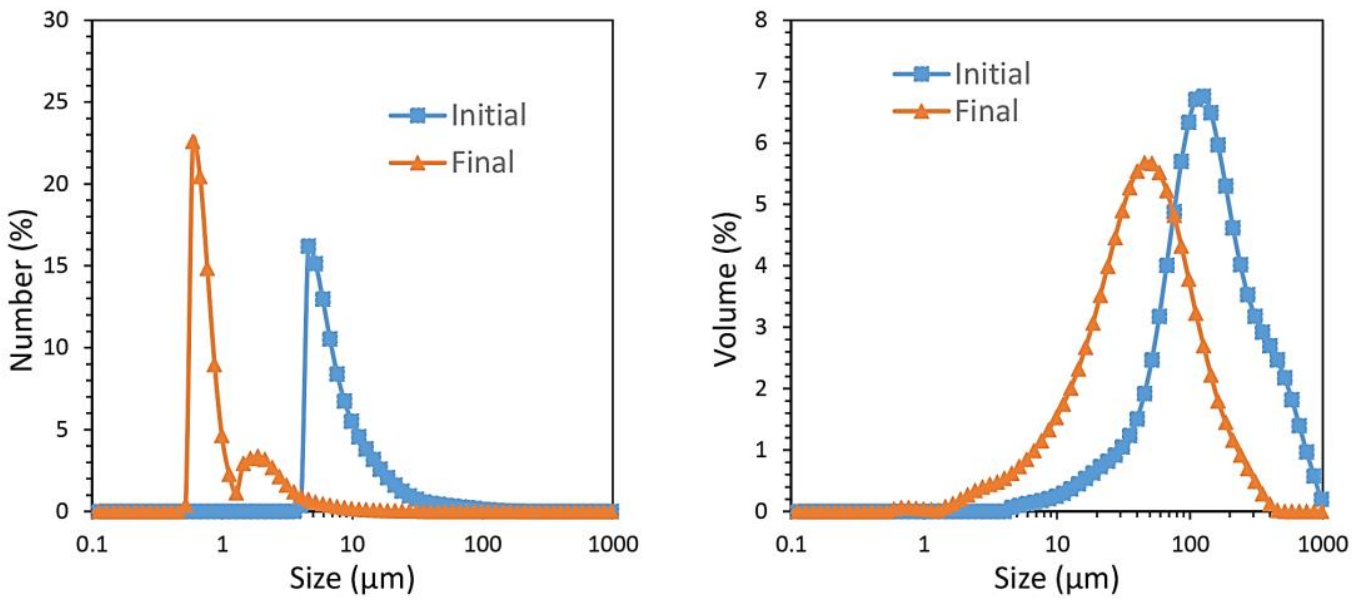

Figure 3. Evolution of number- (left) and volume- based (right) crystal size distribution (CSD) measurements (\%) by laser diffraction for a 30-hour chiral amplification experiment after using preparation method B. Initial CSD is that of the conglomerate Lglutamic acid crystals added prior to the preparation(20 wt $\%$ of the solid phase). Final CSD is the one measured after both preparation and chiral amplification experiment.

Analysis of the solid phase enantiomeric excess of the same samples (30 min, $2 \mathrm{~h}$ and $24 \mathrm{~h}$ ) revealed that the composition remained racemic throughout the crystal transformation process. Therefore, phenomena of preferential enrichment due to crystal transformation can also be excluded ${ }^{45,46}$.

Figure 5 presents optical microscope images of the newly formed conglomerate crystals for the same experiment and over the same time intervals. After $30 \mathrm{~min}$ at $70{ }^{\circ} \mathrm{C}$, no monohydrate crystals are visible and the conglomerate crystal size is significantly smaller compared to that of the initial hydrate crystals. The mean crystal size after $30 \mathrm{~min}$ is measured by laser diffraction at $d_{4,3}=67 \mu \mathrm{m}$ and $d_{1,0}=3 \mu \mathrm{m}$, similar to the final mean crystal size obtained in the chiral amplification experiments preceded by preparation method B. Additionally, the crystal size distribution is quite broad, with several crystals at sizes between 1- $10 \mu \mathrm{m}$. Crystal size seems to decrease even further after $2 \mathrm{~h}$ and at $90{ }^{\circ} \mathrm{C}$ due to some partial dissolution of the crystals at the higher temperature (Figure 5).

Figure 6 presents in-situ microscope pictures of an experiment using a temperature-controlled cell at $70{ }^{\circ} \mathrm{C}$ showing the con- version of the hydrate crystals in the presence of conglomerate seeds at stagnant conditions. It shows that at the early stages of the re-crystallization process, liquid-liquid phase separation might occur, which possibly facilitates the formation of the conglomerate crystals (more information is provided in the Supporting Information). During the fast transformation process, the size of the initial seed population remains roughly unchanged, although they seem to grow very slowly.

The information provided in this section explains the strong effect of the preparation method B on the evolution of the enantiomeric excess in the absence of attrition enhancement. Preparation method B starts with a mixture of two crystal populations at $70{ }^{\circ} \mathrm{C}$ : a) the DL-glutamic acid monohydrate crystals and b) the L- or D-glutamic acid conglomerate seed crystals. At these conditions, the whole DL-glutamic acid monohydrate crystal population swiftly dissolves, leading to high concentration of glutamic acid molecules in the solution phase. Subsequently, the concentration decreases by the fast crystallization of the conglomerate D- and L-glutamic acid crystals. 


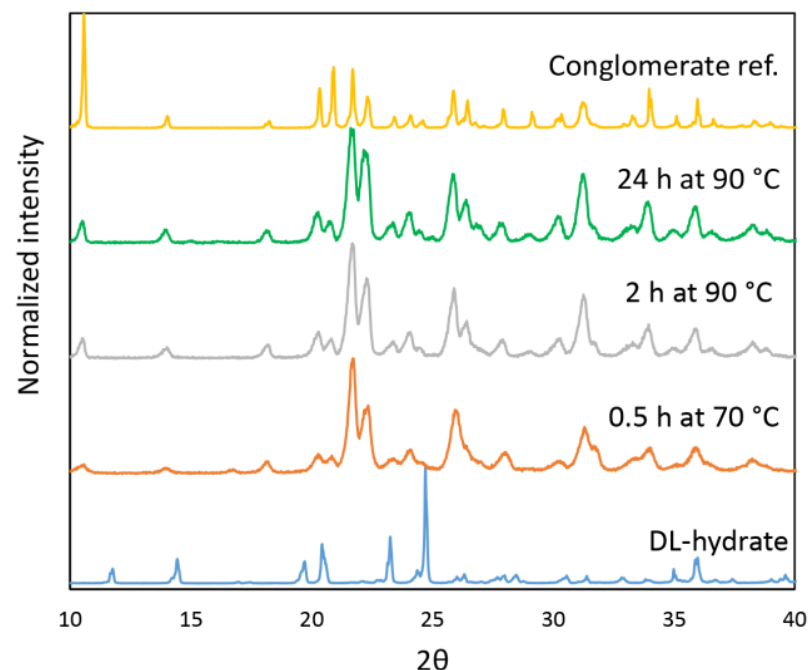

Figure 4. XRPD patterns of samples taken after stirring a DLglutamic acid monohydrate (blue) suspension in acetic acid for: a) $0.5 \mathrm{~h}$ at $70{ }^{\circ} \mathrm{C}$ (orange); b) $2 \mathrm{~h}$ at $90{ }^{\circ} \mathrm{C}$ (grey); c) $24 \mathrm{~h}$ at $90{ }^{\circ} \mathrm{C}$ (green); d) pure conglomerate (yellow).
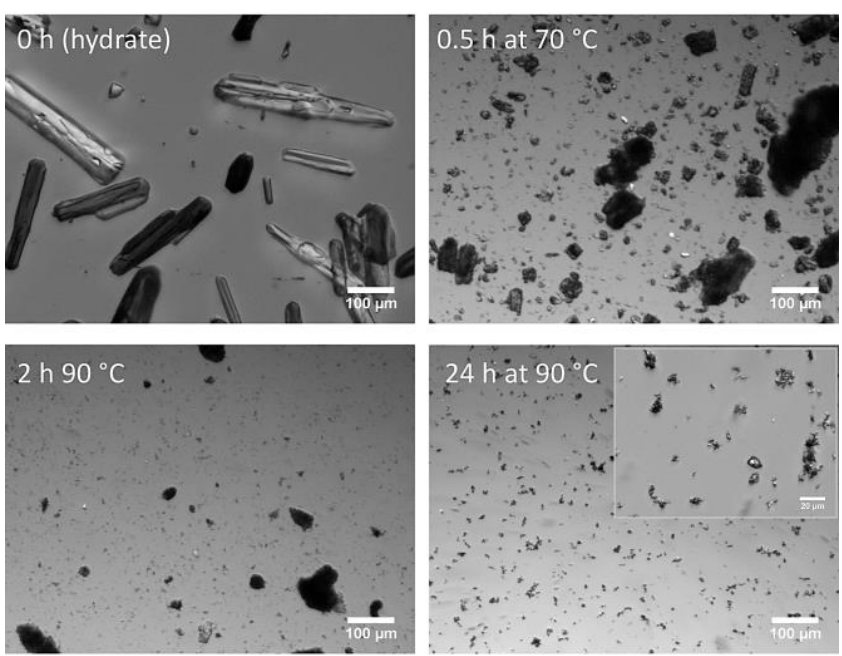

Figure 5. Optical microscope images (room temperature) of the newly formed conglomerate crystals, due to the transformation of the DL-glutamic acid monohydrate crystals (upper left) in acetic acid with stirring, after $0.5 \mathrm{~h}$ at $70{ }^{\circ} \mathrm{C}, 2 \mathrm{~h}$ at 90 ${ }^{\circ} \mathrm{C}$ and $24 \mathrm{~h}$ at $90^{\circ} \mathrm{C}$. White bar corresponds to $100 \mu \mathrm{m}$. In the lower right picture, a magnification is provided (white bar is $20 \mu \mathrm{m}$ in that picture). Dry crystals were suspended in antisolvent (ethanol) before taking the images.

The newly formed population of D- and L-glutamic acid conglomerate crystals is overall racemic and has a significantly lower mean crystal size compared to the initial conglomerate seeds. During this process, the size of the homochiral large seeds does not change significantly, as most of the supersaturation is consumed during the nucleation and growth of the large number of new small conglomerate crystals (Figure 6). Thus, the net result is a strong decrease in the overall mean particle size and the generation of a biased CSD: the counter enantiomer is only present as small sized-crystals, while the preferred enantiomer is present as both small-sized crystals and large seed crystals.
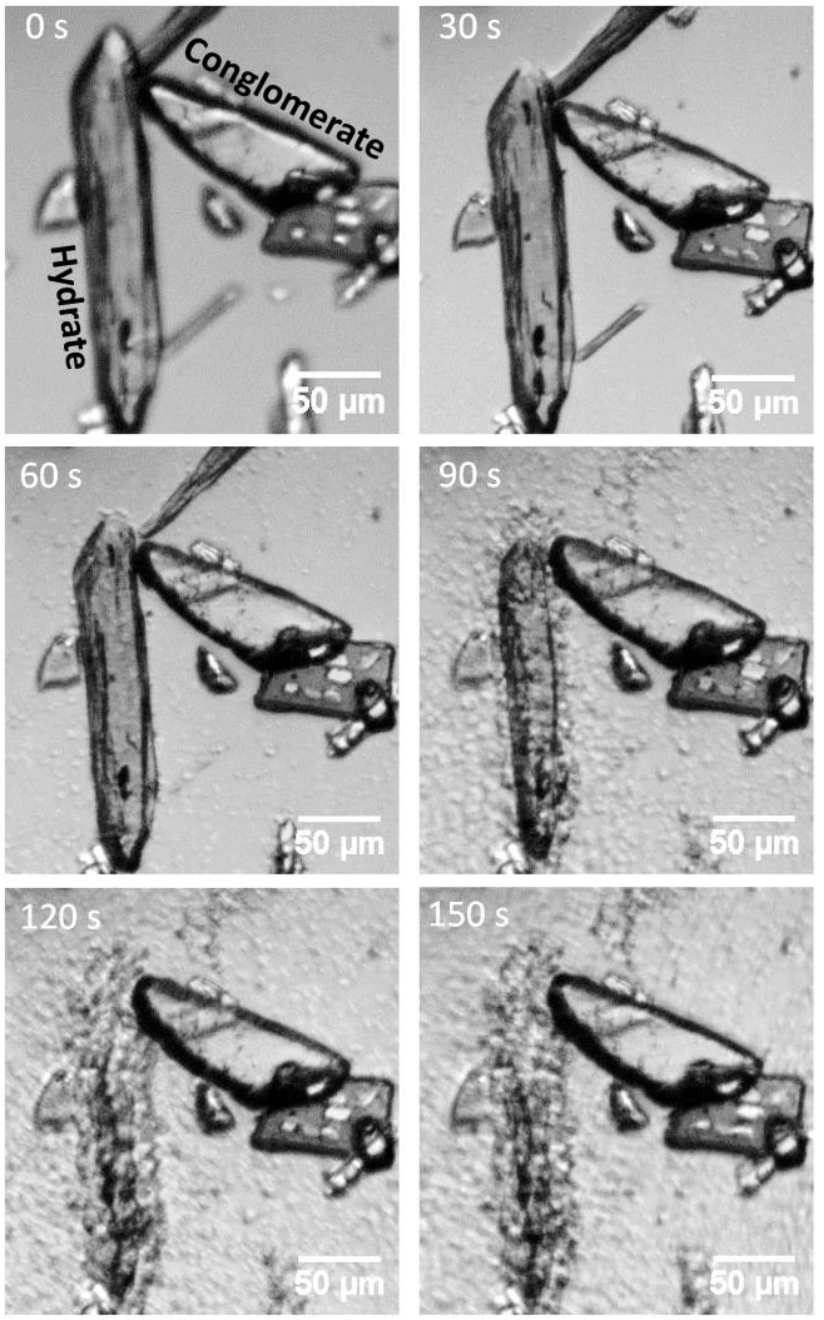

Figure 6. Early stage microscope pictures (every 30 seconds) of the DL-glutamic acid hydrate crystal transformation in the presence of already existing larger conglomerate seeds $\left(70{ }^{\circ} \mathrm{C}\right.$ in acetic acid, stagnant conditions). Conglomerate crystals are not dissolving at the experimental conditions; instead they seem to grow slightly. The crystal transformation seems to progress by liquid-liquid phase separation.

Due to the absence of the racemization catalyst, no significant increase in the enantiomeric excess has occurred yet $(t=0 \mathrm{~h}$ in Figure 1). Subsequently, temperature is increased to $90{ }^{\circ} \mathrm{C}$. It is noted that some increase in the enantiomeric excess pertains also to the increased solubility at the higher temperature leading to partial dissolution of the scalemic mixture.

After the preparation method and the equilibration of the system is at $90{ }^{\circ} \mathrm{C}$, the racemization catalyst is added. The addition of the catalyst marks the start of the chiral amplification process. During the actual experiment i.e. the ripening period, the system remains at constant temperature near equilibrium. At these conditions, the largest crystals (present only as the preferred enantiomer) will tend to grow at the expense of the small ones of both chiralities that dissolve, so that the total surface area and surface energy of the system are reduced. The aforementioned process combined with the racemization reaction, leads to an enrichment of the solid phase towards the preferred enantiomer. The possible occurrence of enantioselective agglomeration of small and seed crystals would speed up this process by removing small crystals of the preferred 
enantiomer from the process. Since the minor enantiomer is only present as small crystals, it may eventually fully dissolve and racemize. Attrition enhancement may not be needed in this process because preparation method B creates suitable initial conditions for fast chiral ripening. A schematic representation of the underlying mechanisms in method B is illustrated in Figure 7.

Chiral amplification experiments in the absence of the crystal transformation. The evidence provided in the previous section strongly suggests that the enhanced rate of increase in enantiomeric excess without attrition, obtained using the combined DL-glutamic acid monohydrate conversion to conglomerate (preparation method B) and subsequent ripening, is a result of the differences in the crystal size distributions of the two enantiomers, artificially engineered by the addition of seeds. In preparation method $\mathrm{B}$, the transformation of the hydrate crystals took place in the presence of enantiopure seeds. Under such conditions, the seeds could grow or induce secondary nucleation and consume the supersaturation generated by the dissolution of the more soluble hydrate crystals. Since slow racemization of amino acids is possible also in acetic acid without any catalyst, such an effect could also lead to gradual increase in the enantiomeric excess.

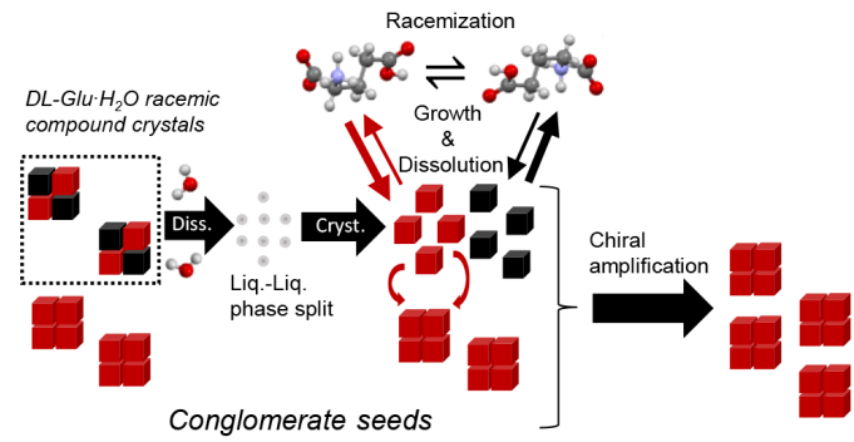

Figure 7. Schematic representation of the influence of an initial racemic crystal transformation to conglomerate (preparation method B) on the enantiomeric enrichment process.

In order to prove that the crystal size difference rather than the dissolution of the hydrate and direct growth of the seeds drives the evolution of the enantiomeric excess, we designed a new experiment, in which the seeds are not present during the crystal transformation. In this experiment, we first re-crystallized the DL-glutamic acid monohydrate crystals in ethanol, under stirring for 1 hour at $60{ }^{\circ} \mathrm{C}$, in order to obtain the conglomerate. The resulting crystals were filtered, dried and subjected to XRPD analysis, laser diffraction and measurement of the solid phase enantiomeric excess (see Supporting Information). The XRPD analysis revealed that the resulting crystals were indeed the conglomerate, with no trace of the hydrate. The mean crystal size of the newly formed conglomerate crystals was measured at $d_{4,3}=74.9 \mu \mathrm{m}$ and $d_{1,0}=3.98 \mu \mathrm{m}$ and the solid phase enantiomeric excess was determined to be $0 \%$ by means of chiral HPLC.

Subsequently, the newly formed conglomerate crystals were directly used in chiral amplification experiments combined with larger L or D conglomerate seed crystals to create size imbalance. Note that in these experiments no further preparation took place.

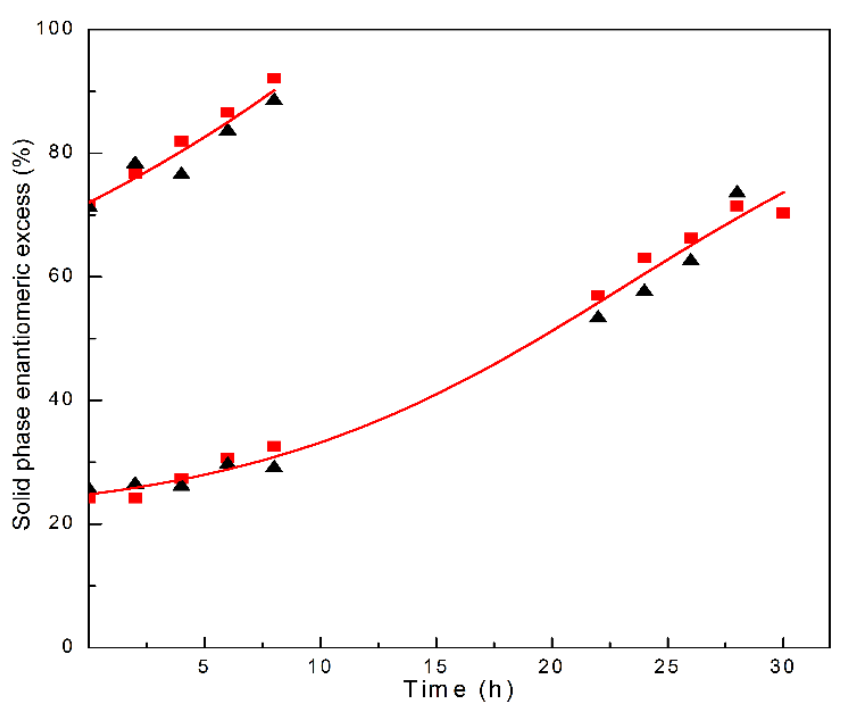

Figure 8. Evolution of solid-phase enantiomeric excess for glutamic acid crystals at $90{ }^{\circ} \mathrm{C}$ without attrition enhancement, at the same conditions. Black triangles: preparation method in the absence of seeds. Red squares: preparation method in the presence of seeds (method B).

Figure 8 displays the temporal evolution of the solid phase enantiomeric excess for the new experiments, in comparison with experiments carried out after preparation method B at the same conditions. In all new experiments, an increase in the enantiomeric excess is observed (black triangles in Figure 8) with time. The enantiomeric excess evolution profile is very similar to the one obtained after using preparation method B (red squares in Figure 8), which suggests that indeed the difference in the size distributions of the two enantiomers is the dominant factor influencing the enantiomeric enrichment process.

Iggland \& Mazzotti in a recent computational study considered cases where growth and dissolution due to crystal size differences coupled with racemization alone can lead to enantiopurity in the absence of attrition ${ }^{47}$. They exemplified that for this "chiral ripening" to take place, a mass imbalance is not sufficient and a difference in the size distribution between the two enantiomers is needed. According to their analysis, this unconventional ripening process is distinct from the "classical" Viedma ripening, where attrition and agglomeration are thought to play an important role. The process described in the present work is an example of such "chiral ripening" without attrition, although the extent to which agglomeration is involved is not yet clear. Importantly, the results suggest that intermediate actions (e.g. grinding or thermal cycling) may be minimized, while still maintaining a fast rate of enantiomeric enrichment as long as the initial conditions for the two enantiomeric crystal populations are carefully tuned (small crystals, broad crystal size distribution, large difference in size between enantiomers).

\section{CONCLUSIONS}

This study demonstrates that isothermal ripening of crystal suspensions in racemizing conditions can, under certain initial conditions, lead to fast solid phase enantiomeric enrichment, even in the absence of attrition enhancement (grinding). Appropriate initial conditions are: a) large number of small particles and b) sufficient size imbalance between the CSDs of the 
two enantiomer crystals. For the examined case of glutamic acid, such conditions are created by the fast and complete solution-mediated transformation of DL-glutamic acid monohydrate crystals to small sized anhydrous conglomerates in the presence of larger homochiral seeds. After the transformation is complete and the racemization catalyst is added, the system contains a newly formed racemic population of small conglomerate crystals together with larger homochiral seed crystals of the preferred enantiomer. Under such conditions, the large crystals of the preferred enantiomer tend to grow at the expense of small crystals, which dissolve. This, combined with the fast racemization, leads to enantiomeric enrichment. The process might be further accelerated due to the possible enantioselective agglomeration of small and seed crystals of the preferred enantiomer. Attrition enhancement is not needed in this process as the initial conditions allow for fast chiral ripening. This is further confirmed by additional experiments that exclude the in-situ transformation and start directly from a mixture of conglomerate crystals of both chiralities with an artificial size imbalance. A similar rate of enantiomeric enrichment is found in these experiments. Overall, the proposed method provides a practical and scalable route to enantiomeric enrichment, by minimizing the use of grinding media and intense attrition conditions. Equally important, the process is applicable to the wider pool of chiral organic compounds that crystallize as racemic crystals and undergo similar crystal transformations. However, more studies are required to optimize this process and to allow reaching enantiopurity starting from lower initial enantiomeric excess values by increasing the deracemization rate and suppressing the formation of stable racemic compounds. Finally, the enantiomeric excess amplification mechanism reported here, at relatively mild temperatures and in the absence of grinding, might provide a likely mechanism for the origin of homochirality in amino acids that are present in biologically relevant molecules.

\section{ASSOCIATED CONTENT}

Supporting Information. Additional results and pictures of the DL-glutamic acid crystal transformation. This material is available free of charge via the Internet at http://pubs.acs.org."

\section{AUTHOR INFORMATION}

\section{Corresponding Author}

* Email: Georgios.Stefanidis@ cit.kuleuven.be

\section{Notes}

The authors declare no competing financial interest.

\section{ACKNOWLEDGMENT}

C. Xiouras acknowledges funding of a Ph.D. fellowship by the Research Foundation-Flanders (FWO). The authors would like to thank Michael Van den Eynde and Dr. Anja Vananroye for providing the optical microscope setup and Kenneth Simoens and Steff Van Loy for their help in the lab. Professor Cristóbal Viedma and Dr. Hugo Meekes are acknowledged for the insightful discussions during the progress of this work. J.H. ter Horst thanks the EPSRC Centre for Innovative Manufacturing in Continuous Manufacturing and Crystallisation (http://www.cmac.ac.uk) for supporting this work (EPSRC funding under grant reference: $\mathrm{EP} / \mathrm{I} 033459 / 1)$.

\section{REFERENCES}

(1) Jean Jacques, A. C.; Wilen, S. H. Enantiomers, Racemates, and Resolutions; Krieger: Malabar, FL, 1994

(2) Lorenz, H.; Seidel-Morgenstern, A. Angew. Chemie - Int. Ed. 2014, 53, 1218-1250.

(3) Coquerel, G. Advances in Organic Crystal Chemistry: Comprehensive Reviews 2015; Tamura, R., Miyata, M., Eds.; Springer Japan: Tokyo, 2015, 393-420.

(4) Viedma, C. Phys. Rev. Lett. 2005, 94, 3-6.

(5) Noorduin, W. L.; Van Enckevort, W. J. P.; Meekes, H.; Kaptein, B.; Kellogg, R. M.; Tully, J. C.; McBride, J. M.; Vlieg, E. Angew. Chemie - Int. Ed. 2010, 49, 8435-8438.

(6) Noorduin, W. L.; Izumi, T.; Millemaggi, A.; Leeman, M.; Meekes, H.; Van Enckevort, W. J. P.; Kellogg, R. M.; Kaptein, B.; Vlieg, E.; Blackmond, D. G. J. Am. Chem. Soc. 2008, 130, $1158-1159$.

(7) Noorduin, W. L.; Bode, A. A. C.; Van der Meijden, M.; Meekes, H.; Van Etteger, A. F.; Van Enckevort, W. J. P.; Christianen, P. C. M.; Kaptein, B.; Kellogg, R. M.; Rasing, T.; Vlieg, E. Nat. Chem. 2009, 1, 729-732.

(8) Kaptein, B.; Noorduin, W. L.; Meekes, H.; Van Enckevort, W. J. P.; Kellogg, R. M.; Vlieg, E. Angew. Chemie - Int. Ed. 2008, 47, 7226-7229.

(9) Hein, J. E.; Huynh Cao, B.; Viedma, C.; Kellogg, R. M.; Blackmond, D. G. J. Am. Chem. Soc. 2012, 134, 12629-12636.

(10) Kellogg, R.; Van der Meijden, M.; Leeman, M.; Gelens, E.; Noorduin, W.; Meekes, H.; Van Enckevort, W.; Kaptein, B.; Vlieg, E. Org. Process. Res. Dev. 2009, 13, 1195-1198.

(11) Spix, L.; Alfring, A.; Meekes, H.; Van Enckevort, W. J. P.; Vlieg, E. Cryst. Growth Des. 2014, 14, 1744-1748.

(12) Spix, L.; Meekes, H.; Blaauw, R. H.; Van Enckevort, W. J. P.; Vlieg, E. Cryst. Growth Des. 2012, 12, 5796-5799.

(13) Spix, L.; Engwerda, A. H. J.; Meekes, H.; Van Enckevort, W. J. P.; Vlieg, E. Cryst. Growth Des. 2016, 16, 4752-4758.

(14) Iggland, M.; Fernández-Ronco, M. P.; Senn, R.; Kluge, J.; Mazzotti, M. Chem. Eng. Sci. 2014, 111, 106-111.

(15) Steendam, R. R. E.; Brouwer, M. C. T.; Huijs, E. M. E.; Kulka, M. W.; Meekes, H.; Van Enckevort, W. J. P.; Raap, J.; Rutjes, F. P. J. T.; Vlieg, E. Chem. - A Eur. J. 2014, 20, 13527-13530.

(16) Steendam, R. R. E.; Harmsen, B.; Meekes, H.; Van Enckevort, W. J. P.; Kaptein, B.; Kellogg, R. M.; Raap, J.; Rutjes, F. P. J. T.; Vlieg, E. Cryst. Growth Des. 2013, 13, 4776-4780.

(17) Wilmink, P.; Rougeot, C.; Wurst, K.; Sanselme, M.; Van Der Meijden, M.; Saletra, W.; Coquerel, G.; Kellogg, R. M. Org. Process Res. Dev. 2015, 19, 302-308.

(18) Sivakumar, R.; Askari, M. S.; Woo, S.; Madwar, C.; Ottenwaelder, X.; Bohle, D. S.; Cuccia, L. A. CrystEngComm 2016, 23, 4277-4280.

(19) Steendam, R. R. E.; Verkade, J. M. M.; Van Benthem, T. J. B.; Meekes, H.; Van Enckevort, W. J. P.; Raap, J.; Rutjes, F. P. J. T.; Vlieg, E. Nat. Commun. 2014, 5, 5543.

(20) Uwaha, M.; Katsuno, H. J. Phys. Soc. Japan 2009, 78, 2-5.

(21) Iggland, M.; Mazzotti, M. Cryst. Growth Des. 2011, 11, 46114622.

(22) McBride, J. M.; Tully, J. C. Nature 2008, 452, 161-162.

(23) Viedma, C. Astrobiology 2007, 7, 312-319.

(24) Rougeot, C.; Guillen, F.; Plaquevent, J.-C.; Coquerel, G. Cryst. Growth Des. 2015, 15, 2151-2155.

(25) Xiouras, C.; Van Aeken, J.; Panis, J.; Ter Horst, J. H.; Van Gerven, T.; Stefanidis, G. D. Cryst. Growth Des. 2015, 15, 5476-5484.

(26) Viedma, C.; Ortiz, J. E.; De Torres, T.; Izumi, T.; Blackmond, D. G. J. Am. Chem. Soc. 2008, 130, 15274-15275.

(27) Viedma, C.; Cintas, P. Chem. Commun. 2011, 47, 12786.

(28) Suwannasang, K.; Flood, A. E.; Rougeot, C.; Coquerel, G. Cryst. Growth Des. 2013, 13, 3498-3504.

(29) Li, W. W.; Spix, L.; De Reus, S. C. A.; Meekes, H.; Kramer, H. J. M.; Vlieg, E.; Ter Horst, J. H. Cryst. Growth Des. 2016, 16, $5563-5570$.

(30) Suwannasang, K.; Flood, A. E.; Coquerel, G. Cryst. Growth Des. 2016, 16, 6461-6467.

(31) Cardew, P. T.; Davey, R. J. Proc. R. Soc. London. A. Math. Phys. Sci. 1985, 398, 415 LP-428.
Davey, R. J.; Cardew, P. T.; McEwan, D.; Sadler, D. E. J. Cryst. Growth 1986, 79, 648-653.

Greco, K.; Bogner, R. J. Pharm. Sci. 2016, 101, 2996-3018. 
(35) Ciunik, Z.; Glowiak, T. Acta Crystallogr. Sect. C-Crystal Struct. Commun. 1983, 39, 1271-1273.

(36) Dunitz, J. D.; Schweizer, W. B. Acta Crystallogr. Sect. CCrystal Struct. Commun. 1995, 51, 1377-1379.

(37) Bada, J. L. J. Am. Chem. Soc. 1972, 94, 1371-1373.

(38) Yamada, S.; Hongo, C.; Yoshioka, R.; Chibata, I. J. Org. Chem. 1983, 83, 843-846.

(39) Ono, T.; Ter Horst, J. H.; Jansens, P. J. Cryst. Growth Des. 2004, 4, 465-469.

(40) Ferrari, E. S.; Davey, R. J. Cryst. Growth Des. 2004, 4, 10611068.

(41) Cornel, J.; Lindenberg, C.; Mazzotti, M. Cryst. Growth Des. 2009, 9, 243-252.

(42) Noorduin, W. L.; Meekes, H.; Van Enckevort, W. J. P.; Millemaggi, A.; Leeman, M.; Kaptein, B.; Kellogg, R. M.; Vlieg, E. Angew. Chemie - Int. Ed. 2008, 47, 6445-6447.

(43) Ricci, F.; Stillinger, F. H.; Debenedetti, P. G. J. Chem. Phys. 2013, 139, 174503.

(44) Steendam, R. R. E.; Van Benthem, T. J. B.; Huijs, E. M. E.; Meekes, H.; Van Enckevort, W. J. P.; Raap, J.; Rutjes, F. P. J. T.; Vlieg, E. Cryst. Growth Des. 2015, 15, 1975-1982.

(45) Tamura, R.; Fujimoto, D.; Lepp, Z.; Misaki, K.; Miura, H.; Takahashi, H.; Ushio, T.; Nakai, T.; Hirotsu, K. J. Am. Chem. Soc. 2002, 124 (44), 13139-13153.

(46) Klussmann, M.; Izumi, T.; Andrew; White, J. P. A.; Armstrong, A.; Blackmond D. G. J. Am. Chem. Soc. 2007, 129, 7657-7660. Iggland, M.; Mazzotti, M. CrystEngComm 2013, 15, 2319.

\section{FOR TABLE OF CONTENTS USE ONLY}

Manuscript Title: Towards deracemization in the absence of grinding through crystal transformation, ripening and racemization

Author list: Christos Xiouras, Emma Van Cleemput, Andries Kumpen, Joop H. Ter Horst, Tom Van Gerven and Georgios D. Stefanidis

\section{TOC graphic:}

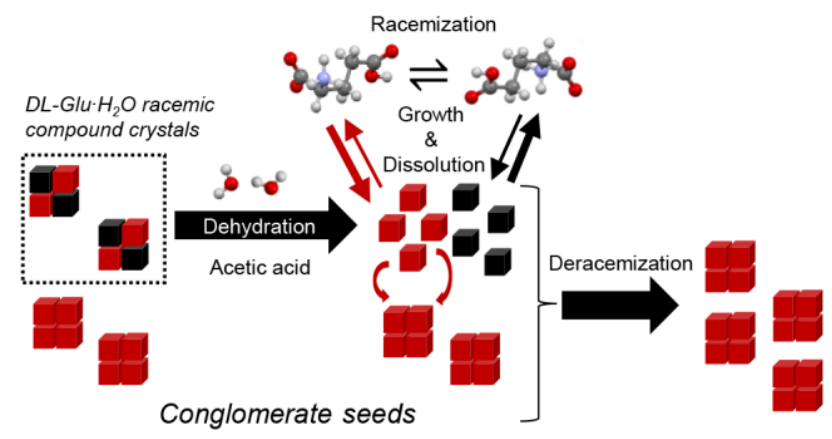

Synopsis: A solution-mediated transformation of racemic compound solvate crystals to conglomerates can intensify the rate of solid-state deracemization during subsequent isothermal ripening experiments, even without intermediate actions (i.e. grinding or thermal cycling). This effect may lead to the development of practical and scalable processes for enantiomeric enrichment of compounds that form metastable racemic crystals and can undergo such transformations. 


\title{
Towards deracemization in the absence of grinding through crystal transformation, ripening and racemization
}

\section{Supporting Information}

\author{
Christos Xiouras $^{\dagger}$, Emma Van Cleemput ${ }^{\dagger}$, Andries Kumpen ${ }^{\dagger}$, Joop H. Ter Horst ${ }^{\ddagger}$, Tom Van
} Gerven $^{\dagger}$ and Georgios D. Stefanidis ${ }^{\dagger *}$

\begin{abstract}
$\dagger$ Process Engineering for Sustainable Systems (ProcESS), Department of Chemical Engineering KU Leuven, Celestijnenlaan 200F, 3001 Leuven, Belgium

† EPSRC Centre for Innovative Manufacturing in Continuous Manufacturing and Crystallisation (CMAC), Strathclyde Institute of Pharmacy and Biomedical Sciences (SIPBS), Technology and Innovation Centre, University of Strathclyde, 99 George Street, Glasgow G1 1RD, U.K.

*Correspondence to: Georgios D. Stefanidis
\end{abstract}

Tel: $+32(0) 16321007$

E-mail: Georgios.Stefanidis@cit.kuleuven.be

\section{RESULTS AND DISCUSSION}

\section{Initial investigation of the DL-glutamic acid monohydrate transformation}

Initially, in order to validate whether a transformation of the DL-glutamic acid monohydrate crystals indeed takes place, experiments were done using in-situ optical microscopy. Figure S1 tracks visually the evolution of the solid phase in acetic acid at $70{ }^{\circ} \mathrm{C}$ in a temperature-controlled cell. Within $100 \mathrm{~s}$ the hydrate crystals dissolve completely and almost instantly a new phase nucleates and starts to grow. Liquid-liquid phase separation (LLPS) seems to occur shortly after the dissolution of the hydrate crystals at regions where the glutamic acid concentration is high enough. It is mentioned that the conditions of this experiment are not directly comparable with the conditions of the chiral amplification experiments and were done only to validate whether a crystal transformation indeed takes place. The newly generated particles seem to follow a polycrystalline growth pattern (spherulitic growth) as it is shown clearly in Figure S2. Spherulitic growth pattern has been observed before during the precipitation of L-glutamic acid under highly supersaturated conditions ${ }^{2}$. At high supersaturations, it has been proposed by Roelands et al. that the spheres are essentially a metastable phase consisting of droplets formed by liquid-liquid phase separation and serve as precursors to the formation of the stable beta form of the conglomerate $^{2}$. In our experiment, high supersaturation is generated due to the significantly higher solubility of the DL-glutamic acid monohydrate crystals compared to the anhydrous conglomerate crystals. In water and at $60{ }^{\circ} \mathrm{C}$, DL-glutamic acid monohydrate has approximately 7 times higher solubility than the pure conglomerate (B) L-glutamic acid ${ }^{3}$. Unfortunately, no 
solubility data of glutamic acid in acetic acid are are available in the literature and the experimental solubility determination proves difficult, especially for the DL-glutamic acid monohydrate, due to the fast crystal transformation.
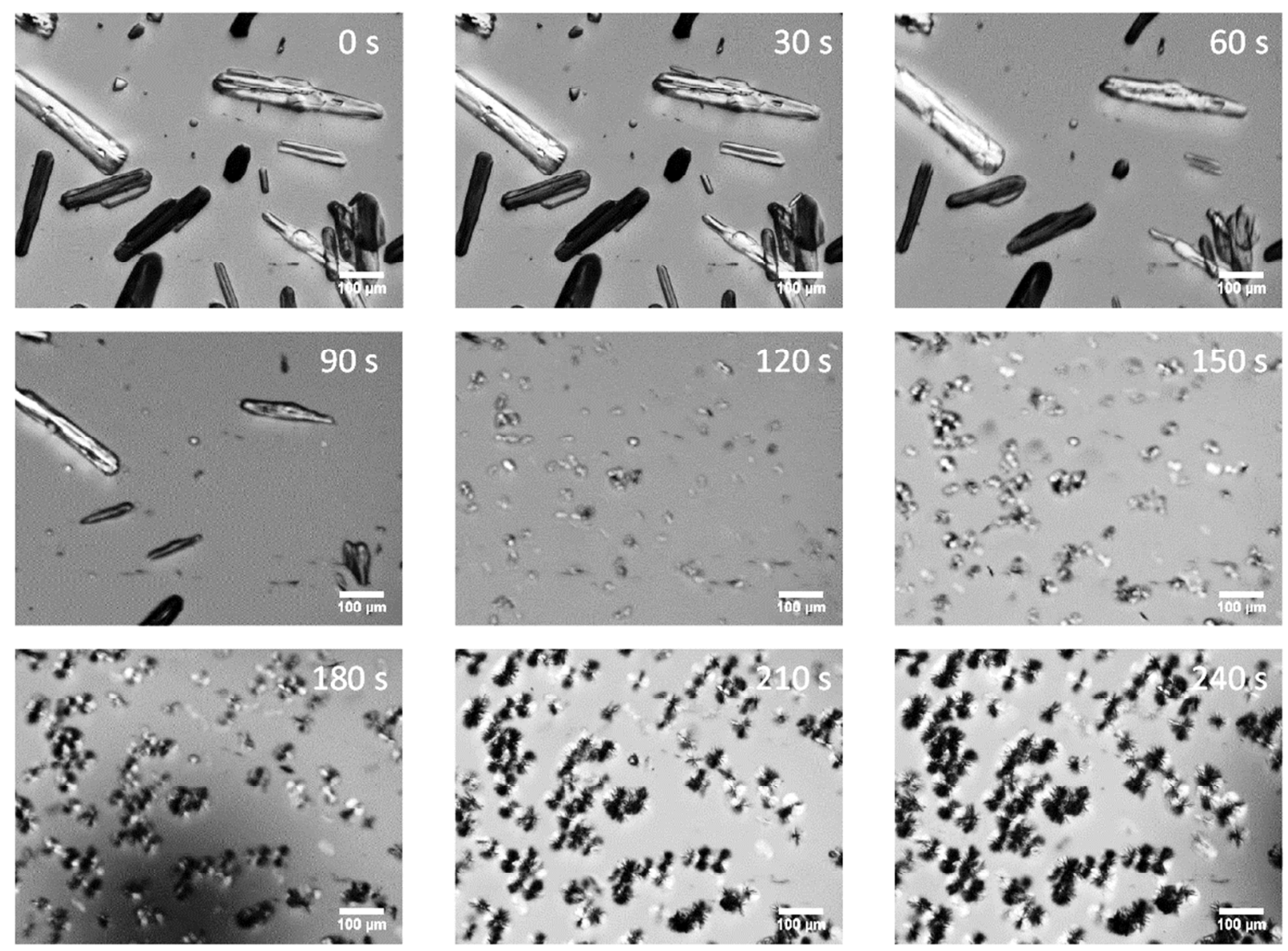

Figure S1. In-situ light microscopy pictures of the DL-glutamic acid hydrate crystal transformation at $70{ }^{\circ} \mathrm{C}$ in acetic acid at stagnant conditions, using a temperature controlled cell. The swift dissolution of the hydrate crystals and the re-crystallization of a new solid phase is clearly observed.
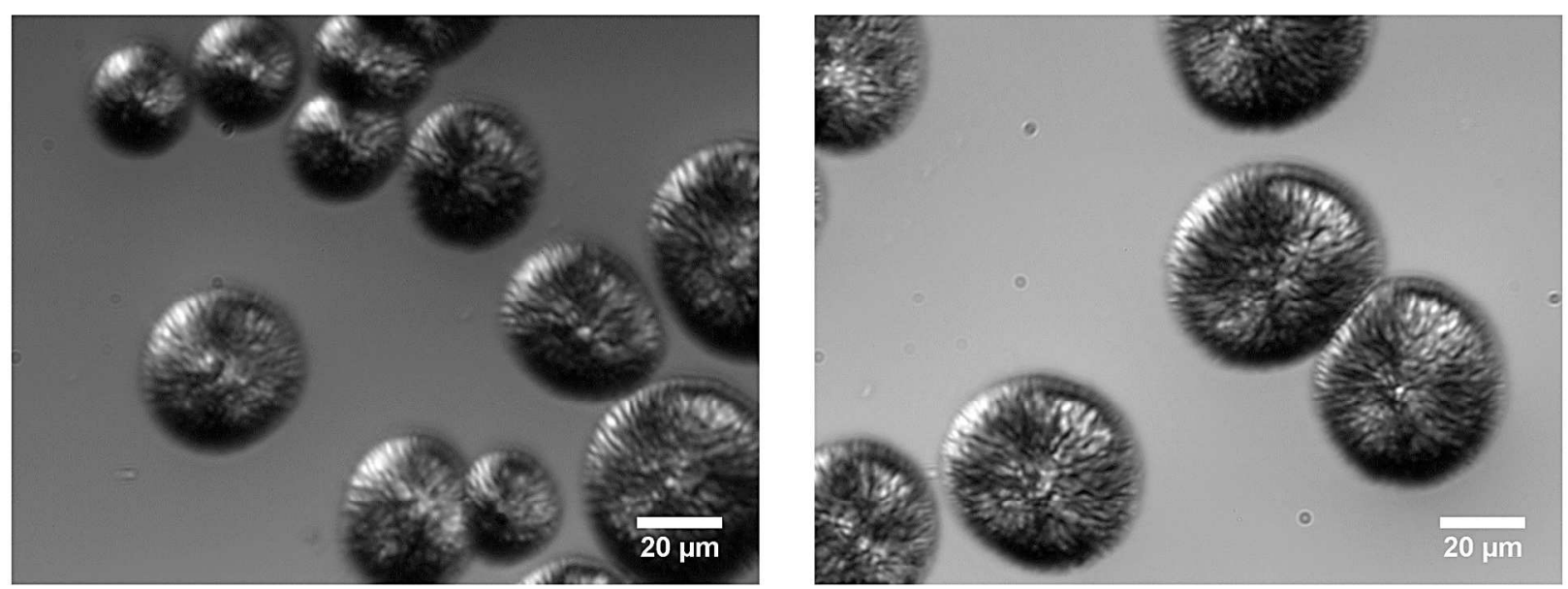

Figure S2. Microscope pictures of the new solid phase obtained after the transformation of the DL-glutamic acid hydrate crystals. The new particles strongly resemble a spherulitic structure.

\section{DL-glutamic acid monohydrate crystal transformation in ethanol}

To obtain a small-sized conglomerate crystal population of glutamic acid, DL-glutamic acid hydrate crystals were re-crystallized in ethanol at $60^{\circ} \mathrm{C}$ for 1 hour. The resulting crystals were characterized before their use in the chiral amplification experiments. The XRPD patterns 
recorded (Figure S3) confirm that the DL-glutamic acid transformation to the conglomerate is successful at these conditions. The volume- and number-based crystal size distributions were also measured and are reported in Figure S4. The mean crystal size of the newly formed conglomerate crystals after extracting them from the mother liquor and drying is measured at $\mathrm{d}_{4,3}=74.9 \mu \mathrm{m}$ and $\mathrm{d}_{1,0}=3.98 \mu \mathrm{m}$, approximately 3 times less than the mean crystal size of the conglomerate seeds. Optical microscope pictures of the conglomerate crystals formed by re-crystallizing DLglutamic acid monohydrate crystals in ethanol are presented in Figure S5.

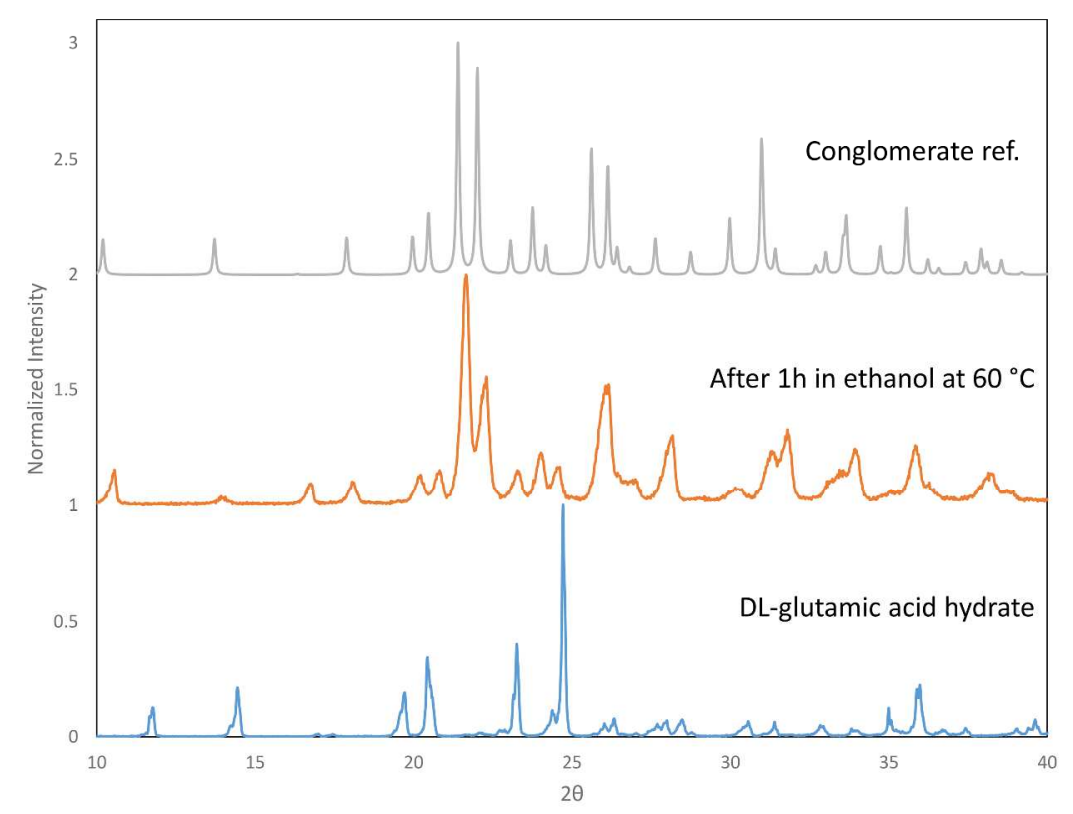

Figure S3. XRPD patterns of DL-glutamic acid monohydrate (blue), after re-crystallization in ethanol at $60{ }^{\circ} \mathrm{C}$ for $1 \mathrm{~h}$ (orange) and conglomerate reference obtained from Cambridge Crystallographic Structure Database (gray). The hydrate crystals convert fully to conglomerates after $1 \mathrm{~h}$ in ethanol at $60^{\circ} \mathrm{C}$.
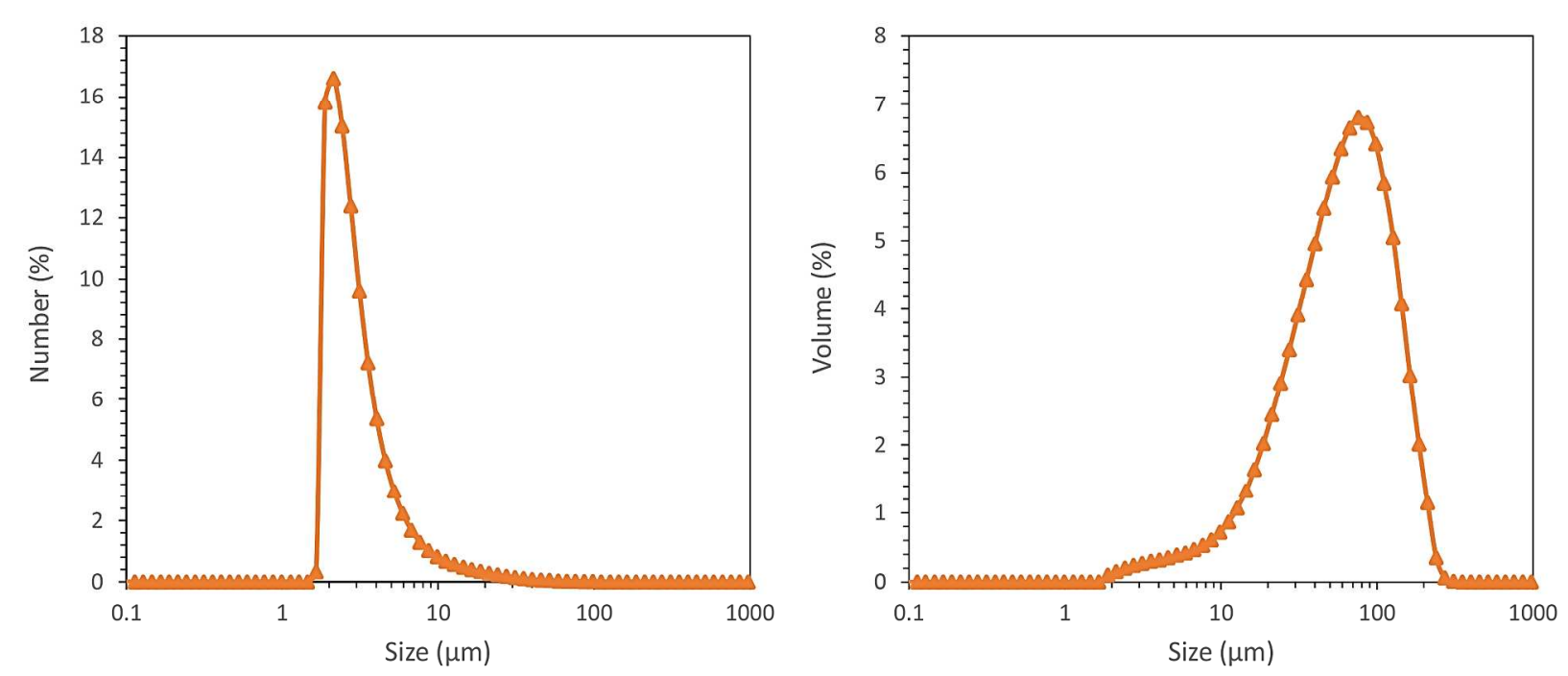

Figure S4. Crystal size distribution measurements of the racemic conglomerate crystals obtained by re-crystallization of DL-glutamic acid monohydrate crystals in ethanol at $60{ }^{\circ} \mathrm{C}$ for 1 hour. The average crystal size is measured at $\mathrm{d}_{4,3}=74.9 \mu \mathrm{m}$ and $\mathrm{d}_{1,0}=3.98 \mu \mathrm{m}$. 


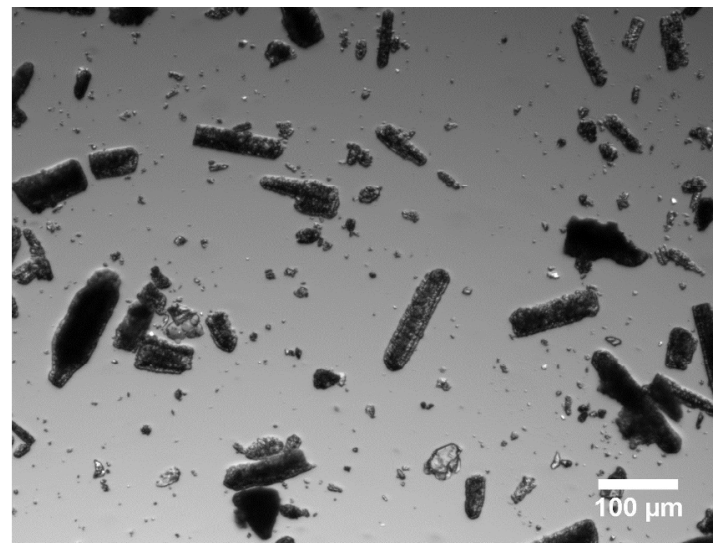

Figure S5. Microscope image of the resulting crystals after re-crystallization of the DL-glutamic acid monohydrate crystals in ethanol at $60^{\circ} \mathrm{C}$ for $1 \mathrm{~h}$.

\section{REFERENCES}

[1] Yamada, S.; Hongo, C.; Yoshioka, R.; Chibata, I. J. Org. Chem., 1983, 83, 843-846.

[2] Roelands, M.C.P.; Ter Horst, J.H.; Kramer, J.M. Jansens, P. J. AIChe Journal. 2007, 53, 354362 .

[3] Ogawa, T.; Akashi, T. U.S. Patent 2,940,998, 1960. 